\title{
GESTÃO DE UM NÚCLEO DE APOIO AO ESTUDANTE NA UNIVERSIDADE
}

http://dx.doi.org/10.5902/2318133827373

\author{
Filipe Sales \\ Imago estudos e práticas psicológicas, Brasil. \\ Márcia Paixão \\ Universidade Federal de Santa Maria, Brasil.
}

\begin{abstract}
Resumo
Este artigo é resultado de uma pesquisa de especialização em Gestão Educacional que foi realizada junto ao Ânima da UFSM. Buscou-se compreender qual era a percepção de gestão no Ânima a partir da equipe de profissionais com vistas a um espaço de atenção e cuidado aos estudantes do ensino superior. A metodologia baseou-se numa sessão reflexiva, com dois eixos centrais que acompanharam a conversa. Pela análise dos dados constatou-se que a equipe de profissionais compreende o que é gestão, como esta funciona, contudo não consegue identificar qual é o modelo norteador do Núcleo de Apoio do Estudante.

Palavras-chave: gestão, equipe multiprofissional, ensino superior.
\end{abstract}

\section{MANAGEMENT OF MULTIDISCIPLINARY ACCOMPANIMENTS IN A CENTER FOR STUDENT SUPPORT}

\begin{abstract}
The university is composed of a space of knowledge, socialization, personal and professional growth. In this universe, the way in which this institution will be managed is highlighted, so that it can provide students with everything they are looking for when joining. This work aimed to understand the perception of management in the Aim, from the team of professionals with a view to a space of attention and care to students of higher education. The methodology developed was based on a reflexive session, with two central axes that accompanied the conversation, based on the research question. From the analysis of the data, it was found that the professional team understands what management is, how it works, however, it can not identify which is the management model of the Student Support Center.

Key-words: management, multiprofessional team, higher education.
\end{abstract}




\section{Introdução}

sociedade contemporânea enfrentou mudanças socioeconômicas, políticas e
culturais, assim como, concomitantemente a elas, ocorreram no Brasil
modificações no âmbito da esfera educacional. Essas transformações transpassam os muros das instituições educacionais e adentram em sala de aula, onde acontecem o diálogo e a troca entre professores, estudantes e seus colegas. Essa relação dialógica entre os atores é de suma importância e, muitas vezes, a falta desta pode ocasionar problemas relativos ao desempenho da aprendizagem, adaptação e convivência desses estudantes, levando-os a buscarem auxílio na assistência educacional estudantil, onde uma equipe de profissionais capacitados, dentre eles psicólogos, psicopedagogos e educadores especiais, estarão à sua disposição para auxiliar em questões relacionadas a problemas ou dificuldades educacionais.

No universo acadêmico a forma como a instituição é gerida é destaque, pois é através disso que será possível proporcionar aos estudantes tudo aquilo que procuram ao ingressar no ensino superior. Uma questão importante está relacionada à dificuldade que os gestores possuem em gerir uma universidade, os docentes, a sala de aula, além de uma infinidade de setores e de pessoas. Dessa forma é possível perguntar: como será que ocorre este processo de gestão?

Não existem muitos estudos sobre a forma como essa gestão ocorre dentro da universidade, considerando todas essas variáveis. Devido a isso, torna-se importante pesquisar sobre esse tema que suscita perguntas e diálogos.

Durante 0 processo de escuta e intervenção psicológica com os pacientes, estudantes da UFSM com e sem deficiência, que são atendidos no Ânima, foi possível perceber que os mesmos abordam em seu discurso problemas relacionados ao ambiente familiar - com seus pais e, principalmente, com suas mães - que são anteriores ao seu ingresso na universidade. As dificuldades desencadeavam problemas de relacionamento com colegas e professores, indagações quanto à profissão que iriam exercer, dúvidas quanto à escolha do curso, entre outros. Com base nisso emergiu um questionamento: como a equipe de profissionais que atuam no Ânima compreende o processo de gestão na qual estão inseridos?

Apesar de o sistema educacional ter passado por transformações no que concerne o acesso e permanência de estudantes com ou sem necessidades educacionais, ainda há algumas questões, tais como: qual será o entendimento dos profissionais que atuam no Núcleo de Apoio ao Estudante no ensino superior? Será que o modelo de gestão vigente influencia no modo de fazer os encaminhamentos e atendimentos aos estudantes ou sofre a influência destes profissionais?

Pretendíamos, especificamente, conhecer os reflexos da gestão nas atividades efetuadas pelos profissionais no Ânima, averiguar qual é a compreensão deles e delas sobre a gestão e verificar qual é a modalidade de gestão existente no Ânima.

A metodologia baseou-se numa sessão reflexiva com dois eixos centrais: percepção da gestão do Ânima e desafios da gestão democrática. Essa conversa aconteceu com três bolsistas que são membros da equipe do Núcleo de Apoio ao Estudante - Ânima - e que exercem as funções de educador especial, psicopedagogo e psicólogo no atendimento aos estudantes no setor. 


\section{Breve apanhado histórico sobre a gestão educacional}

A escola é a segunda morada de todo o ser humano que busca se socializar, desenvolver o seu conhecimento, enfim, humanizar-se. Por sua vez, a escola desempenha uma função de suma importância na evolução e desenvolvimento de seus estudantes e para que isto ocorra, é fundamental que haja uma equipe - diretores, professores, funcionários, comunidade - que faça parte desse processo, para tanto é preciso que se estruture uma gestão coesa, democrática e participativa.

Para inserirmos aqui o tema gestão é pertinente que façamos uma breve explicação sobre a origem das palavras gestão e administração. Provêm do latim, em que o primeiro termo significa governar, conduzir, dirigir, e o segundo tem um significado mais restrito, defendendo os interesses daquele que o possui, constituindo-se em uma aplicação do termo gerir. A palavra gestão remete à gestação, gerir, dar a vida e como tal, nos agrada, porque em se tratando da escola, o objetivo principal é fazer com que a vida dos seres humanos que passam pela mesma, se torne mais promissora, digna, justa e humana (Silva, 2007).

O tema educação, tornou-se gradativamente um assunto central no cenário político nacional e internacional. A escola, em termos globais, tem visto o seu desenvolvimento e afirmação fortemente influenciados pela localização dos países e das regiões na esfera mundial. Segundo Antônio Teodoro (2003), "como todos os fenómenos globais, a escola tem uma raiz local. Trata-se de um modelo que se desenvolveu na Europa e que, paulatinamente, se torna universal, decorrendo a sua força precisamente da capacidade demonstrada em se afirmar não como o melhor sistema, mas como o único possível e imaginável" (p. 17).

A crescente expansão da escola em todos os níveis e classes sociais, impulsionou o estabelecimento de modelos de organização pedagógica, capazes de abarcar um crescente número de estudantes. Com esse objetivo desde o século 19 originou-se uma dinâmica escolar que procurou abranger a tarefa de ensinar a muitos como se fosse um só, modificando o âmbito escolar e transformando-o em um elemento central, de homogeneização linguística e cultural, proporcionando consecutivamente a consolidação do estado-nação. Essa padronização da educação ocorreu concomitantemente a uma mudança no contexto educacional, isto é, os valores estabelecidos no decorrer do século passado, as regras e metas que regularam a estruturação da escola da maneira como a conhecemos na nossa jornada educacional, estão em crise. Conforme Teodoro (2003),

a escola para todos, ao abrir as suas portas a novos públicos escolares, não apenas no ensino elementar, como o fez no passado, mas agora no ensino médio e até, tendencialmente, no ensino superior, significa uma realidade qualitativamente distinta, com a qual os decisores políticos, os professores, os estudantes e suas famílias, a opinião pública em geral têm uma manifesta dificuldade em entender. (p. 18)

As instituições de ensino, sejam elas de nível básico, médio ou superior, possuem um modelo de gestão singular que se adequa às necessidades de cada um. Alguns modelos de gestão são mais centralizados, outros mais descentralizados. Na perspectiva de superar a justaposição de etapas fragmentadas, que tem caracterizado a organização 
da educação escolar até seu advento, a Lei de Diretrizes e Bases da Educação Nacional LDB - aponta para uma concepção educacional fundada no princípio de continuidade entre educação infantil, ensino fundamental e ensino médio, caracterizando a educação básica, a ser universalizada.

No Brasil, as reformulações de cunho político, econômico e social foram conduzidas pelos moldes neoliberais de gestão, principalmente na década de 1990, dessa forma, fortaleceram o estado regulador propiciando além dos níveis de eficiência e produtividade dos serviços públicos, uma nova estrutura de organização e gestão, flexibilizando e repassando para a iniciativa privada funções que caberiam somente ao poder estatal (Lordêlo; Dazzani, 2009).

$\mathrm{Na}$ esfera educacional a iniciativa privada proporcionou uma nova estrutura e organização, especialmente no ensino superior. Nas últimas décadas foi possível visualizar um novo cenário não somente referente ao crescimento de instituições privadas em todo país, subsidiado por uma grande flexibilidade da LDB, mas também, com uma atualizada configuração de ensino constituindo dessa forma espaços de formação, visando a suprir as demandas do mundo globalizado em constante transformação, requisitando o estabelecimento de um perfil eficiente e capaz de suprir as demandas do mercado. Dentre elas configuram-se aquelas que integram o ensino superior. Esse campo se caracteriza pela própria modernização universitária, por intermédio de uma preocupação com a produção de conhecimento para a formação do capital humano, com o intuito de atender a demanda da globalização e suprir os anseios da sociedade, que visualizam na educação a condição essencial para a entrada no mercado de trabalho (Lordêlo; Dazzani, 2009).

A gestão educacional é compreendida como um processo de tomada de decisões em relação ao projeto político-pedagógico e seu desenvolvimento é visto como um gerenciamento do ensino, que deve estar de acordo com a análise da forma como a sociedade está organizada, com uma avaliação das questões econômicas, políticas e sociais existentes nessa sociedade. Essas questões englobam as relações interpessoais, em cujo meio encontramos a relação professor-aluno, que direta ou indiretamente encontra-se permeada pela gestão escolar, como a trama de um tecido na qual os fios se entrelaçam para formar o todo. A gestão abrange aspectos que visam à mobilização, motivação e coordenação dos atores que integram o âmbito educacional. Dirigir uma instituição escolar implica colocar em ação os elementos do processo organizacional planejamento, organização, avaliação - de forma coesa e articulada. Por sua vez, o papel representado pelo gestor deve desempenhar a função de liderança, no clima de organização escolar, visando proporcionar a liberdade de decisão no processo educativo e não esfera burocrática (Borges, 2008).

Para que haja uma gestão educacional efetiva, participativa e democrática é preciso uma parceria entre a instituição educacional e a comunidade, para que aquela seja de fato inclusiva e democrática. Com base nessa lógica de gestão o papel exercido pelo gestor deve ser pautado na construção de relacionamentos sociais, realizando articulações entre a equipe de profissionais, alunos, comunidade, com o intuito de uma realização conjunta, que englobe ações que visem ao diálogo com as pessoas e uma 
articulação com a equipe de profissionais (Silva, 2013). O gestor precisa compreender que agindo de forma individual, não conseguirá administrar todos os entraves da escola. O caminho é a descentralização, isto é, o compartilhamento de responsabilidades com alunos, pais, professores e funcionários.

Uma das principais características que se destacam, dentre as inúmeras características fundamentais que integram a gestão democrática, é a autonomia. A autonomia na história das idéias pedagógicas sempre foi associada ao tema de liberdade individual e social, da ruptura com esquemas centralizadores de transformação da sociedade (Gadotti, 1997).

$\mathrm{Na}$ atualidade, os princípios e desafios infligidos pela gestão democrática vêm sendo debatidos pelos educadores e todos que estão direta ou indiretamente envolvidos neste processo. A gestão democrática representa um grande desafio na operacionalização das políticas educacionais e no cotidiano escolar. Essa modalidade de gestão baseia-se na Constituição de 1988, que postula "gestão democrática do ensino público, na forma da lei" como um de seus princípios (art. 206, Inciso VI).

A Constituição Federal de 1988 estabeleceu princípios para a educação brasileira, dentre os quais: obrigatoriedade, gratuidade, liberdade, igualdade e gestão democrática, sendo esses regulamentados através de leis complementares. Conforme os parâmetros estabelecidos pela LDB:

Enquanto lei complementar da educação, a Lei de Diretrizes e Bases da Educação Nacional (LDB no 9.394/96) estabelece e regulamenta as diretrizes gerais para a educação e seus respectivos sistemas de ensino. Em cumprimento ao art. 214 da Constituição Federal, ela dispõe sobre a elaboração do Plano Nacional de Educação - PNE (art. 9º), resguardando os princípios constitucionais e, inclusive, de gestão democrática. A elaboração do PNE, conforme exposto nos textos legais, visa a elucidar problemas referentes às diferenças socioeconômicas, políticas e regionais, bem como às que se referem à qualidade do ensino e à gestão democrática. O PNE trata dos diferentes níveis e modalidades da educação escolar, bem como da gestão, do financiamento e dos profissionais da educação. Esse plano, aprovado em 2001 pela (Lei no. 10.172/2001), traz diagnósticos, diretrizes e metas que devem ser discutidos, examinados e avaliados, tendo em vista a democratização da educação em nosso país. (Oliveira; Moraes; Dourado, 2010, p. 1)

Para que haja uma implementação efetiva da gestão participativa é preciso conhecer as condições e limitações para que a mesma seja adotada. Nas instituições, escolas, empresas, dependendo dos papeis e funções que forem desempenhadas pelas pessoas, isto é, quanto mais rígidos eles forem estabelecidos, ou seja, quanto maior for a burocratização, menor será a participação e implicação de seus membros com relação a organização do trabalho como um todo. A cultura escolar vigente na maior parte das instituições de ensino ainda é burocrática e centralizadora, ou seja, a compreensão acerca do conceito de gestão e do gestor escolar é totalmente mal empegada e mal compreendida, pois, de fato, é visível a profunda "confusão" que ocorre acerca do entendimento de tais conceitos, em sua aplicação prática, isto é, no momento em que a teoria, é visualizada no cotidiano escolar. 
Tal incompreensão está diretamente relacionada à proporção da instituição, ou seja, quanto maior ela for, maior será a segmentação de seu trabalho, impessoalidade e distanciamento entre eles, e consecutivamente, menor a participação das pessoas envolvidas no processo de gestão (Lück, 2006).

A gestão participativa é importante na estruturação de uma gestão democrática escolar, uma vez que possibilita o envolvimento de profissionais e da clientela no processo de tomada de decisões, bem como no adequado funcionamento da organização educacional. Com isso, proporciona melhor conhecimento dos objetivos e metas, da estrutura organizacional e de sua dinâmica, das relações da escola com a comunidade, favorecendo, assim, uma proximidade mútua entre educadores, alunos, pais e comunidade.

O papel desempenhado por um gestor educacional, em um contexto de uma gestão democrática e participativa, deve demonstrar interesse pela atuação dos educadores, funcionários e alunos, orientando e motivando o labor em equipe, assim como o compartilhamento de experiências na busca pelas conquistas de resultados promissores e coletivos, além de incentivar a realização de projetos escolares com a finalidade de tornar uma qualidade de ensino digna para a clientela (Lück, 2009).

\section{O Núcleo de Apoio ao Estudante - Ânima - da UFSM}

Iniciamente convêm buscar a origem da palavra para entender sua vinculação com as propostas pedagógicas e de gestão do Ânima. Segundo Araújo (2011), a respeito da palavra ânima

etimologicamente a palavra anima (ânima) ou sua variação animus são originários do latim, e tanto animus como anima podem ser traduzidos por "alma" ou "mente", dependendo do contexto em que se encontram. A raiz latina animus é cognato em grego de anemos, vento, respiração; e do sânscrito aniti, ele respira. Em italiano e espanhol, a palavra anima é traduzida como alma. (p. 1)

Contudo, ânima, segundo o conceito da psicanálise analítica de Jung, tem outro significado:

Para a Psicologia Analítica, o arquétipo da anima (termo em latim para alma), constitui o lado feminino no homem, e o arquétipo do animus (termo em latim para mente ou espírito), constitui o lado masculino na psique da mulher. Ambos os sexos possuem aspectos do sexo oposto, não só biologicamente, através dos hormônios e genes, como também, psicologicamente através de sentimentos e atitudes. Sendo a persona a face externa da psique, a face interna, a formar o equilíbrio são os arquétipos da anima e animus. O homem traz consigo, como herança, a imagem de mulher. Não a imagem de uma ou de outra mulher especificamente, mas sim uma imagem arquetípica, ou seja, formada ao longo da existência humana e sedimentada através das experiências masculinas com o sexo oposto. (Portillo, 2016, p. 2)

O atendimento ao estudante na UFSM iniciou suas atividades no ano de 1970 , com o intuito de implantar um serviço de apoio e orientação ao estudante. Após três anos, em 1973, foi ratificada o funcionamento do Serviço de Orientação Educacional - SOE. 
Inicialmente, o Serviço foi vinculado à Pró-Reitoria de Assuntos Estudantis, localizando-se no prédio da administração central, estruturando-se com base nos estatutos da UFSM daquele período. O SOE tornou-se um órgão suplementar do atual Centro de Educação (Pozobon et al., 2008).

Esse órgão desempenhou esta função em toda comunidade universitária e santamariense até 1991, no momento onde ocorreu a cisão da equipe de profissionais que ali atuavam. Contudo, em 1995, o serviço foi reativado, sob a denominação de Serviço de Orientação Educacional Psicopedagógica e Profissional do Ensino Superior - Soeppes. Já em 1998 houve uma nova reestruturação do serviço, sendo então criado o Núcleo de Apoio ao Estudante da UFSM - Ânima (Pozobon et al., 2008).

O Ânima transformou-se em um núcleo de ensino, pesquisa e extensão do Centro de Educação da UFSM, onde permaneceu até 2013. A composição de profissionais compreende as áreas da Psicologia, da Psicopedagogia, e da Pedagogia. As atividades realizadas por estes profissionais são as seguintes: atendimento psicológico individual aos estudantes que procuravam o serviço ou eram encaminhados pelas coordenações de curso ou professores, além de atividades de grupos. Com o passar dos anos, o Ânima trilhou novos caminhos, metas e objetivos que se caracterizaram fundamentalmente pelo viés educacional psicopedagógico. Devido a isso, a partir de 2010, além dos atendimentos psicológicos individuais aos estudantes, tornou-se um local que visa a favorecer aos processos de ensino e aprendizagem, com enfoque nas questões psicopedagógicas, tanto institucionais, quanto clínicas. Atualmente, é denominado de Núcleo de Apoio Psicopedagógico na Educação Superior (Siluk et al., 2014).

O Núcleo fica disponível aos estudantes que necessitam de atendimento psicopedagógico, com 0 intuito de auxiliá-los nas dificuldades de aprendizagem, buscando orientá-los quanto aos seus hábitos de estudo, carreira e aconselhamento profissional, encaminhamento para avaliação. Esse atendimento tem o objetivo de contribuir para o desenvolvimento e adaptação acadêmica, possibilitando uma melhor integração do estudante ao contexto do ensino superior (Siluk et al., 2014). Em média, são realizados cerca de 2.000 atendimentos anualmente, entre atendimentos psicológicos, psicopedagógicos e educacionais especializados.

A equipe de profissionais compreende: dois servidores, um gestor responsável pelo Ânima, um psicólogo e uma pedagoga, além dos profissionais que são bolsistas de programas de pós-graduação da UFSM, que estão vinculados a projetos de pesquisa e que são selecionados mediante editais semestrais ou anuais (Ânima, 2016).

\section{Dialogando e refletindo acerca de alguns achados}

A coleta de dados envolveu o estabelecimento de algumas categorias. Na categoria intitulada Percepção da gestão do Ânima percebeu-se entendimento dos profissionais acerca do tema percepção sobre a gestão.

Gestão, para mim, é o sinônimo ou está relacionada a organização, centralização, planejamento, digamos, a pessoa que é a gestora de um local, é a que centraliza a organização e tem para si algumas responsabilidades, em relação aquele setor (Participante 1). 
O meu entendimento sobre gestão é mais ou menos o mesmo da participante 1. Acredito que a gestão tá dentro deste contexto de gerenciar, de administrar de organizar, eu acho que para o gestor fazer gestão, para poder coordenar e liderar uma equipe de uma maneira coesa, assim, compreendendo tanto o lado da equipe quanto o lado das pessoas que estão atendendo, seja na área da saúde ou em uma empresa (Participante 2).

Quando se fala de gestão, ao meu ver remete a uma questão de uma empresa, já penso mais para este lado, mais organizacional, devido a vivência que eu tenho, de recrutamento e seleção. Um viés do meu olhar, eu penso logo nisso, é bem o que a participante 1 e 2 falaram, gerenciar, organizar (Participante 3).

Conforme as questões explicitadas acima, é possível inferir que os profissionais compreendem a gestão como um encargo institucional-administrativo, que visa ao controle e a organização. No entanto, também foi dito que o gestor, além de coordenar e liderar, necessita compreender e auxiliar a sua equipe de profissionais. É possível inferir que as concepções de gestão ainda são moldadas por princípios de teorias administrativas, que ainda integram as práticas de gestão na universidade.

O trabalho do gestor é uma função que exige empenho não somente dele, como também, de todos envolvidos no processo de gestão:

Acho que depende muito da equipe, porque tu trabalha com pessoas, algumas são mais críticas, outras menos, e muitas vezes é difícil trabalhar com os profissionais que não conseguem lidar com estas intempéries (Participante 1).

Isso mesmo! Alguns não conseguem trabalhar bem e aceitar críticas. Por exemplo, acontece alguma coisa aqui no setor e é papel do gestor chamar aquele profissional, ou para chamar a atenção, ou para conversar, para tentar resolver (Participante 2).

Concordo com a participante 2, muitas vezes, o profissional não lida bem com críticas e leva aquilo para o lado pessoal, é papel do gestor chamar a atenção para alguma coisa que o profissional fez, ou deveria ter feito, é função deles chamar a atenção destes (Participante 3).

Um ponto muito destacado retrata a importância do trabalho conjunto entre a equipe e a gestão, isto é, uma gestão onde todos participam do processo integralmente. Além do que foi explicitado acima, os participantes discorreram sobre a relação e a importância de uma equipe na gestão, assim como a mesma pode ser visualizada, por meio de aspectos positivos e negativos:

A pessoa não sabe receber críticas, por exemplo, acho que esta questão é um ponto negativo de ser gestor, que está muito relacionado a equipe que tu vai ter, assim, como pode possuir uma equipe muito coesa, parceira e que saiba trabalhar (Participante 1).

E mesmo que a equipe saiba receber críticas e consiga trabalhar no coletivo, tem pessoas que possuem esta dificuldade e por isso, muitas vezes o gestor tem que trabalhar com os conflitos entre os colegas, tem que ser o mediador dessas situações e, por isso, muitas vezes ele trabalha 
nesta "saia justa" e este é o ponto negativo em relação ao gestor, saber lidar com as diferentes personalidades que vai ter dentro daquele setor. Para mim, é o que é mais difícil (Participante 2).

Eu acho que de pontos positivos, de negativos de ser gestor é a tomada de decisão, porque por exemplo, em um conflito de equipe, às vezes, você vai ter que se posicionar, se a equipe estiver discordando, terá que saber como se posicionar naquele momento (Participante 3).

Complementando o que foi dito acima, é um desafio da gestão estabelecer uma integração com a equipe e conseguir criar um vínculo de confiança e participação entre os profissionais. Podemos compreender o funcionamento de uma gestão por meio da participação dos membros que integram a mesma. A participação pode ser visualizada como uma maneira de compartilhamento de decisões, responsabilidades, seja por decisões estabelecidas de forma conjunta ou como saída para a problematização das intempéries, que poderão ocasionar em uma evolução das relações que englobam os processos de gestão ou como uma forma de engajamento, representando o nível mais pleno de participação, que segundo Luck (2006) "implica envolver-se dinamicamente nos processos sociais e assumir responsabilidade por agir com empenho, competência e dedicação, visando promover os resultados propostos e desejados" (p. 44).

Um aspecto muito debatido foi o da formação profissional do gestor e a influência desta no processo de gestão:

Muitas vezes o gestor, não tem a formação adequada para a função do gestor. Pode ser que o gestor tenha a felicidade de 'dar conta das coisas', mas pode ser que dependendo da formação que ele tenha, talvez não consiga (Participante 3).

Concordo com a participante 3, em áreas "duras" vai ser difícil, para o gestor gestar a gestão, e fazer este posicionamento ou lidar com esta equipe. Então, a questão da relação interpessoal, muitas vezes, as maiorias dos gestores não tem curso de gestão, são pessoas formadas em diversas áreas (Participante 2).

Esta questão, do profissional que atua como gestor, como já mencionado, é importante ter este conhecimento, porque muitas vezes são coisas específicas, e o gestor precisa ter um conhecimento específico daquela área, para poder dar conta muitas vezes de algumas situações (Participante 1).

É importante ressaltar que a formação inicial de gestores, em nível superior, esteve presente desde as reformas iniciais do curso de Pedagogia. Por isso, fica ao encargo dos sistemas de ensino a função, como também, a responsabilidade de promover, organizar e efetuar a criação de cursos de capacitação para a preparação dos futuros gestores (Rocha, 2009).

Outro aspecto discutido pelos participantes foi sobre a influência da gestão em suas práticas profissionais:

Do meu ponto de vista, a gestão não influencia em minhas práticas profissionais. A gestora do setor não tem a formação que eu tenho, nossas formações são distintas, mas ela é minha superior. Ela procura sempre 
conversar com a gente, estar a par das coisas que acontecem, sempre pergunta as nossas opiniões, mesmo eu sendo a profissional da área qualificada para o atendimento, eu nunca tomo uma decisão sem antes falar com ela (Participante 1).

Justamente! Eu acho importante que a gestora do setor, esteja ciente das coisas que nós fazemos, pois não assinamos nada sozinhos, até mesmo, porque ela também faz parte deste processo (Participante 2).

Eu acho que influencia nos meus atendimentos! Porque se a minha gestão diz que não é para 'mim' preencher prontuário, eu não vou preencher! Eu acho que influencia, porque quem coordena faz de uma maneira, e às vezes na minha prática, eu penso de forma diferente (Participante 3).

Realmente, concordo com a participante 3! Influencia! Não posso dizer se é de uma maneira positiva ou negativa, mas influencia. Porque é a gestão que vai coordenar e tomar as maiores decisões do que será feito, das diversas situações que ocorrem no serviço. A minha gestão tem uma formação diferente da minha, e entende as coisas de maneira diferente (Participante 1).

Indo ao encontro do que foi explicitado, Evelina Dagnino (1994) postula que

os mecanismos institucionais de participação como esforços de controle social do Estado, visando à maior transparência e publicização das políticas públicas, e vê uma atuação efetiva, na sua formulação, de setores da sociedade civil desprovidos de outras formas de acesso a espaços de decisão. Ademais, estudos analisam os pressupostos da relação entre Estado e sociedade, na medida em que apresentam os diferentes níveis ou padrões democratizantes da sociedade brasileira, ressaltando as contradições e os diferentes resultados, de acordo com as variadas esferas de poder e a correlação das forças políticas, econômicas ou sociais. (Dagnino, 1994, p. 3 )

Outra categoria foi intitulada Desafios da gestão democrática e se relaciona aos desafios aos quais a gestão pode vir a infligir a equipe. Desta forma, destaca-se o que segue:

Para mim, a nossa gestão é aberta, para que a gente sugira, reivindique, como gostaríamos que as 'coisas' melhorassem, mudassem! É aberta para nos ouvir! (Participante 2).

Só que muitas vezes, nós somos atendidos em questões que propomos e outras vezes não! Eu pelo menos sinto desta maneira, que a gente é aberto para ser ouvido! Mas não quer dizer, que aquilo que a gente está pedindo ou acreditando, vá ser aceito! (Participante 1).

Eu concordo com a participante 2! Eu acho também que nós sempre temos essa liberdade, para expor aquilo que pensamos, mas, no entanto, nem sempre seremos atendidos em relação ao que solicitamos (Participante 3).

Os aspectos comentados acima vem ao encontro do que Rocha (2009) postula:

A partir da participação na organização e gestão do trabalho escolar, os professores podem estar aptos a tomar decisões coletivamente; construir o projeto político pedagógico da escola; compartilhar com os outros as 
preocupações; desenvolver o espírito de solidariedade; tonar-se parte da escola assumindo a responsabilidade pela mesma e investir no seu preparo profissional. (p. 12)

Outro aspecto abordado foi em relação às questões institucionais que permeiam a gestão:

Acredito que existam questões que sejam maiores, que se sobrepõe ao que sugerimos, solicitamos. Algumas 'coisas' não podem ser feitas, mesmo que a gestão por vezes concorde conosco, pois, foge a alçada da mesma (Participante 2).

Devido a questões institucionais! (Participante 3).

Exatamente! Mesmo ela sendo gestora responsável por este setor, faz parte de uma hierarquia que também recebe ordens! (Participante 1).

Nos trechos abaixo são apresentados aspectos relacionados ao modelo de gestão vigente no setor e as possibilidades que as bolsistas percebem em relação à gestão democrática:

Acho que existem alguns fatores que poderiam ser diferentes, mas 'fogem' a vontade da gestora! São de competência de um setor, que pertence a um outro nível de hierarquia! Digamos da própria Universidade, da própria infraestrutura, do número de profissionais, isso sim, acho que poderia ser diferente! (Participante 2).

O Ânima, faz parte de um núcleo maior, ele é dependente, digamos, ele está inserido em uma coordenadoria com outros profissionais, que estão envolvidos, nem sempre estes em, algumas situações, possuem o mesmo ponto de vista. Como eu posso dizer isso, como mudar isso? (Risos) É complicado! (Participante 1).

Para que haja mudança, é necessário que possamos opinar e que sejamos ouvidos! Que haja diálogos, e alguns acordos e flexibilizações, para que as coisas possam mudar um pouco (Participante 3).

Esta questão de infraestrutura e número de profissionais, independe até mesmo da coordenadoria a qual estamos vinculados, é da instituição da universidade! (Participante 1)

Atualmente, eu estou satisfeita, eu estou aqui a 1 ano, e tiveram questões as quais me deparei quando iniciei, que me incomodaram, mas já foram modificadas (Participante 3).

\section{Considerações finais}

É importante salientar que os referenciais teóricos referentes ao escopo do trabalho foram difíceis de serem encontrados, pois, atualmente, não existem muitos estudos sobre a forma como ocorre a gestão dos acompanhamentos multiprofissionais na universidade.

A sessão reflexiva realizada com as profissionais que realizavam atendimentos no Núcleo de Apoio aos Estudantes foi muito esclarecedora e suscitou alguns questionamentos para outro trabalho. Pela sessão percebeu-se que as pessoas entrevistadas não compreendem claramente qual é o modelo de gestão vigente, no 
entanto, apresentam argumentos sobre o que vivenciam e visualizam acerca da gestão do setor.

Ficou claro que, na concepção das profissionais, a denominação sobre gestão de uma forma geral e específica do Núcleo pode ser visualizada e compreendida como um instrumento burocrático, mecanicista, de conotação administrativa, semelhante aos moldes de uma empresa. Isto é, uma gestão administrativa que gere uma instituição, uma empresa, uma entidade social de pessoas, a ser gerida ou administrada.

Quanto ao papel do gestor as participantes explicitaram que ele possui uma importância fundamental para o bom andamento dos processos de gestão. Contudo, tiveram dois aspectos abordados em relação ao gestor: por um lado, foi descrito como alguém que tem como função principal resolver os problemas que ocorrem no Núcleo, como também, necessita ser ponderado, conciliador, mediador, que valorize e saiba trabalhar e compreender a equipe que atua conjuntamente com o mesmo. Outro aspecto abordado pelos participantes foi sobre a modalidade de gestão do Núcleo. Os participantes não souberam dizer exatamente se ela era democrática ou não, pois, na realidade, não compreendiam sobre o que seria uma gestão democrática. Contudo verbalizaram que a gestão do local valoriza o trabalho em equipe, assim como escuta as reclamações e sugestões, porém nem todas são atendidas.

No que concerne à influência da gestão nos atendimentos aos estudantes, as entrevistadas foram categóricas ao relatar que sofrem forte influência não só da gestão do Núcleo, como também da universidade. No entendimento das participantes a mesma inflige forte influência institucional, tanto na gestão, quanto na equipe e também no trabalho que é desempenhado com os estudantes. Um ponto importante mencionado pelos participantes foi a importância do gestor possuir formação profissional na área de gestão.

Para finalizar, a partir dos dados produzidos pela pesquisa, foi possível compreender que essa gestão seria mista, isto é, em parte participativa, em outra centralizadora devido às questões institucionais. No entanto, a gestão e a equipe estão abertas ao diálogo, assim como, possuem atributos muito importantes para a constituição de uma gestão democrática, como: Abertura ao diálogo, compreensão sobre o trabalho a ser feito, abertura a novas perspectivas, equipe coesa e comprometida, ou seja, possuem subsídios para futuramente reformular ou construir novas formas de atuação e gestão.

\section{Referências}

ANDRADE, Ilza Araújo Leão. O desenho das políticas públicas e a dinâmica de seus Conselhos Gestores: um estudo comparativo das áreas de saúde, assistência social e trabalho. ENCONTRO NACIONAL DA ANPOCS, 24, 2002. Anais ... Caxambu: Anpocs, 2002, p. 1-9.

ÂNIMA, Site do Ânima. 2017. Disponível em <http://coral.ufsm.br/anima/index.php/equipe>. Acesso em 17 mar. 2016.

ARAÚJO, Ana. Ânima: 0 que significa? Disponível em $<$ http://www.anadaraujo.com.br/detalheconteudo.asp?idconteudo=106>. Acesso em 20 jul. 2016. 
BENEVIDES, Mesquita, Vitória. A construção da democracia no Brasil pós-ditadura militar. In: FÁVERO, Osmar; SEMERARO, Giovanni (org.). Democracia e construção do público no pensamento brasileiro. Petrópolis: Vozes, 2002, p. 10-30.

BORGES, Heloisa da Silva. Organização do trabalho pedagógico e gestão escolar. Manaus: UEA/Valer, 2008.

BRASIL. Constituição Política do Império do Brazil. Rio de Janeiro, 1824. Disponível em <http://www.planalto.gov.br/ccivil_03/constituicao/constituicao24.htm>. Acesso em 17 ago. 2016.

BRASIL. Lei de Diretrizes e Bases da Educação Nacional, Lei 9394/96.

BRASIL. Lei 10.172, de 9 de janeiro de 2001. Aprova o Plano Nacional de Educação e dá outras providencias. Diário Oficial da União. Brasília, DF, 10 jan. 2001.

BUSS, Rosinete Bloemer Pickler. Gestão escolar: cadernos de estudos. Indaial: Asselvi, 2008.

COUTINHO, Carlos Nelson. Democracia e socialismo. São Paulo: Cortez, 1992.

CUNHA, Eudes Oliveira; CUNHA, Maria Couto. A gestão escolar e sua relação com o desempenho da escola: Um estudo em duas escolas em Salvador, Bahia: Brasil. In: CONGRESSO IBERO-BRASILEIRO DE POLÍTICA E ADMINISTRAÇÃO DA EDUCAÇÃO, 3, 2012. Anais ... Zaragoza: UZ/Anpae, 2012, p. 15-25. Disponível em <https://repositorio.ufba.br/ri/bitstream/ri/9266/1/Eudes\%20Oliveira\%20Cunha.pdf>. Acesso em 13 fev. 2016.

DAGNINO, Evelina. Os movimentos sociais e a emergência de uma nova noção de cidadania. In: DAGNINO, Evelina (org.). Os anos 90: política e sociedade no Brasil. São Paulo: Brasiliense, 1994, p. 1-7.

DIAS, José Augusto. Gestão da escola. In: MENESES, João Gualberto de Carvalho et. al. Estrutura e funcionamento da educação básica. São Paulo: Pineira, 1998, p. 15-30.

FERREIRA, Aurélio Buarque de Holanda. Dicionário da língua portuguesa. Curitiba: Positivo, 2010.

FÁVERO, Osmar; SEMERARO, Giovanni (orgs.). Democracia e construção do público no pensamento brasileiro. Petrópolis Vozes, 2002.

GADOTTI, Moacir; ROMÃO, José, Eustáquio. Autonomia da escola: princípios e propostas. São Paulo: Cortez, 1997.

GOMES, Maria das Graças Correia. Gestão participativa: concepções e percepção de participação na visão dos que atuam na escola pública da rede municipal de Maceió/AL. 2011.

Disponível

em

<http://www.anpae.org.br/simposio2011/cdrom2011/PDFs/trabalhosCompletos/comunicac oesRelatos/0350.pdf>. Acesso em 13 fev. 2016.

GOHN, Maria da Glória Marcondes. Conselhos gestores e participação sociopolítica. São Paulo: Cortez, 2000.

GRACINDO, Regina Vinhaes. Gestão democrática da escola e do sistema. In: Curso técnico em gestão escolar: Profuncionário. Módulo 2. Brasília: MEC/CEAD/UnB, 2007.

HORA, Dinair Leal. Educação e gestão educacional na sociedade brasileira contemporânea: algumas reflexões. Revista Linhas, Florianópolis, v. 4, n. 2, 2003, p. 1-23.

KRAHE, Elizabeth Diefenthaeler.; WIELEWICKI, Hamilton de Godoy. Formação docente, pedagogia universitária e mudanças de racionalidade: contribuições ao debate sobre 
políticas educativas. ENCONTRO INTERNACIONAL DE PESQUISADORES DE POLÍTICAS EDUCATIVAS, 3, 2008. Anais ... Porto Alegre: Ufrgs, 2008, p. 133-138.

LUCK, Heloísa. Gestão educacional: uma questão paradigmática. São Paulo: Vozes, 1999.

LUCK, Heloísa. A gestão participativa na escola. São Paulo: Vozes, 2006.

LUCK, Heloísa. Liderança em gestão escolar. Rio de Janeiro: Petrópolis, 2008.

LUCK, Heloísa. Dimensões da gestão escolar e suas competências. Curitiba: Positivo, 2009.

LIBÂNEO, José Carlos. Organização e gestão da escola: teoria e prática. Goiânia: Alternativa, 2008.

LIBÂNEO, José Carlos et. al. Educação escolar: políticas, estrutura e organização. São Paulo: Cortez, 2007.

LISBOA, Magno da Nóbrega. A relevância da gestão democrática e participativa no contexto educacional. Paraíba: UEPB, 2014.

TENÓRIO, Robinson Moreira; ANDRADE, Maria Antonia Brandão. Avaliação da educação superior no Brasil: desafios e perspectivas. In: LORDÊLO, Jose Albertino Carvalho; DAZZANI, Maria Virgínia. Avaliação educacional: desatando e reatando nós. Salvador: UFBA, 2009, p. 31-56.

PEREIRA, Noádia Munhoz; SILVA, Marcelo Soares Pereira. Gestão democrática na educação superior e as tendências de gestão presentes no conselho universitário. SIMPÓSIO BRASILEIRO DA ANPAE, 23, 2007. Anais ... Porto Alegre: Anpae/Ufrgs, $2007 . \quad$ Disponível em <http://www.anpae.org.br/congressos_antigos/simposio2007/358.pdf>. Acesso em 11 out. 2016.

MACHADO, Maria Aglaê de Medeiros. Políticas e práticas integradas de formação de gestores educacionais. In MACHADO, M. A. M. Centro de Estudos e Pesquisas em Educação, cultura e ação comunitária. Gestão educacional: tendências e perspectivas. São Paulo: Cenpec, 1999.

OLIVEIRA, João Ferreira; MORAES, Karine Nunes; DOURADO, Luiz Fernandes. Gestão escolar democrática: definições, princípios e mecanismos de implementação. Minas Gerais, p.1-13, 2010. Disponível em <http://escoladegestores.mec.gov.br/site/4sala_politica_gestao_escolar/pdf/texto2_1.pdf>. Acesso em 15 out. 2016.

PORTILLO, Vanilde Gerolim. Anima e animus. Portal Psique Objetiva, São Paulo, p. 2, dez. 2016. Disponível em <https://psiqueobjetiva.wordpress.com/2010/04/23/anima-eanimus/>. Acesso em 12 jul. 2016.

POZOBON, Luciane Leoratto (org.). Apoio estudantil: reflexões sobre o ingresso e permanência no ensino superior. Santa Maria: UFSM, 2008.

ROCHA, Roberto. A gestão descentralizada e participativa das políticas públicas no Brasil. Revista Pós Ciências Sociais. São Luís, v. 1, n. 11, 2009, p. 1-30.

SILVA, Ana Maria. Gestão participativa na escola e os desafios a serem alcançados. Portal Educação, Campo Grande, 2013, p. 1-6, Disponível em <http://www.portaleducacao.com.br/educacao/artigos/48709/gestao-participativa-naescola-e-os-desafios-a-serem-alcancados\#ixzz4GxHvWTyG>. Acesso em 11 out. 2016.

SILVA, Josias Benevides. Um olhar histórico sobre a gestão escolar. Educação em Revista, Marília, v. 8, n. 1, 2007, p. 21-34. 
SILUK, Ana Cláudia Pavão; POZOBON, Luciane Leoratto; PAVÃO, Silvia Maria de Oliveira. $O$ atendimento educacional especializado: processos de aprendizagem na universidade. In: SILUK, Ana Cláudia Pavão; POZOBON, Luciane Leoratto; PAVÃO, Silvia Maria de Oliveira. Ações e perspectivas para o atendimento educacional especializado no ensino superior. Santa Maria: UFSM, 2014, p. 1-15.

SANTOS, Francisca Martins; VALDÉS, Ignácio Estévez. A gestão escolar relativa ao processo docente educativo e o papel orientador do gestor. Manaus: UEA, 2008, $90 f$. Monografia (especialização em Gestão Escolar). Universidade do Estado do Amazonas. Disponível em <http://br.monografias.com/trabalhos3/gestao-escolar/gestaoescolar.shtml>. Acesso em 20 set. 2016.

SOUSA, Valdivino Alves. A Gestão Educacional e a LDB Artigos de Educação e Pedagogia. Portal Educação, Campo Grande, jan. 2008. Disponível em: $<$ http://www.portaleducacao.com.br/pedagogia/artigos/2366/a-gestao-educacional-e-aldb>. Acessado em: 20 set. 2016.

TEODORO, Antônio. Globalização e educação: políticas educacionais e novos modos de governação. São Paulo: Cortez, 2003.

TRIGUEIRO, Michelangelo Giotto Santoro. Universidades públicas: desafios e possibilidades no Brasil contemporâneo. Brasília: UnB, 1999.

VIEIRA, Sofia Lerche. Educação e gestão: extraindo significados da base legal. In. CEARÁ. Novos paradigmas de gestão escolar. Fortaleza: Seduc, 2005, p. 7-20.

Filipe Sales é graduado em Psicologia e tem mestrado em Educação pela UFSM.

Endereço: Rua Ernesto Lopes, 39 - 97110-280 - Santa Maria - RS - Brasil.

E-mail: psifilipe@hotmail.com.

Márcia Paixão é graduada em Pedagogia, mestre em Ciências Sociais Aplicadas e doutora em Educação, todos pela Universidade do Vale do Rio dos Sinos.

Endereço: Avenida Roraima, 1000 - 97105-900 - Santa Maria - RS - Brasil.

E-mail: marciapaixao12@gmail.com.

Recebido em 27 de maio de 2017.

Aceito em 7 de agosto de 2017. 